\title{
BIM ADOPTION ISSUES IN INFRASTRUCTURE CONSTRUCTION PROJECTS: ANALYSIS AND SOLUTIONS
}

\author{
SUBMITTED: March 2021
}

REVISED: April 2021

PUBLISHED: May 2021

EDITOR: Robert Amor

DOI: $10.36680 /$ j.itcon.2021.015

\author{
Andrew Pidgeon \\ School of Computing, Engineering and Digital Technologies, Teesside University; \\ A.Pidgeon@tees.ac.uk
}

\author{
Nashwan Dawood \\ School of Computing, Engineering and Digital Technologies, Teesside University; \\ N.N.Dawood@tees.ac.uk
}

SUMMARY: The objective of this paper is to assess and outline both the value and inefficiencies of Building Information Modelling (BIM) within Construction Infrastructure projects, and to provide a comparative and conclusive analysis via the underpinning academic literature and industrial reporting respectively. Further, semistructured interviews were undertaken with a range of industry experts to add greater evidence at the application and execution stage, leading onto the proposal of a framework solution to gain advantage due to the implementation of BIM and counter some of the outlined inefficiencies and issues raised.

The aims and objectives of the research study were to develop a methodology that brings to the forefront issues with the adoption of BIM, and to propose a framework in order to provide clarity on resolving these issues to gain an advantage. The methodology consists of four parts which are:

1) Undertaking a systematic literature review of academic and a critical review of industrial literature

2) Analysing, contesting and supporting literature by undertaking a data collection exercise with a range of industry experts who are delivering construction projects and in particular infrastructure via BIM

3) Providing a comparative analysis between data collection, academic and industrial literature in a holistic format

4) Proposing a framework focused on countering the disadvantages and inefficiencies in the adoption of BIM.

There is also evidence of a disconnect due to both the overwhelming nature of BIM (acronyms, competing standards and technology) in that people are unsure what to implement and when, with a lack of objective focus on what the goals and advantages at a project level. The research concludes with a comparative synthesis of results and by outlining a framework solution focused on applying objective focus as part of the application process and requirements, supporting goal attainment and appropriate/agreed measurements of BIM.

KEYWORDS: Building Information Modelling (BIM) Adoption, Digital Construction, Design Implementation, Goals, Project Measurement

REFERENCE: Andrew Pidgeon, Nashwan Dawood (2021). BIM Adoption Issues in Infrastructure Construction Projects: Analysis and Solutions. Journal of Information Technology in Construction (ITcon), Vol. 26, pg. 263285, DOI: 10.36680/j.itcon.2021.015

COPYRIGHT: (C) 2021 The author(s). This is an open access article distributed under the terms of the Creative Commons Attribution 4.0 International (https://creativecommons.org/licenses/by/4.0/), which permits unrestricted use, distribution, and reproduction in any medium, provided the original work is properly cited. 


\section{INTRODUCTION}

In 2011, the UK Government set out in prescribing a UK Building Information Modelling (BIM) Mandate within its Government Construction Strategy (HM Government, 2012). The intention by UK Government was to forge together and strengthen project stakeholders at the project delivery stage with a requirement that all 'centrally procured Construction contracts shall require fully 'collaborative 3D BIM' from 2016 onwards. Furthermore, this mandate sought to achieve a ' $20 \%$ saving' through efficiencies via adoption and advancements realised through anticipated value, as well as improving the quality, timeliness and productivity of Project Delivery of Collaborative BIM via Digital methods. This intention here is to also incorporate new digital ways of working as part of the UK BIM Framework Roadmap (UK BIM Alliance, 2020).

The expectation was that over time, digitisation across project's, from initial feasibility studies through to the execution and delivery stages would result in efficiencies gained alongside the development of specifications and standards, with focus on Digital Engineering and BIM advancements. The standardised processes were and are namely the PAS1192 suite of specifications (BIM Level 2) and the more recent ISO19650-1:2018 and ISO196502:2018 (UK BIM Framework), with inclusion of Digital best practice, seamless sharing of information and a collaborative approach to Information Management and delivery. Further, ISO19650-1:2018 (BSI, 2018) states that BIM is defined as being 'The use of a shared digital representation of a built asset to facilitate design, construction and operation processes to form a reliable basis for decisions'.

A timeline of these standardisation developments alongside the BIM Mandate, frameworks and focused groups is shown below in Figure 1, sourced from the UK BIM Framework (UK BIM Alliance, 2020). Whilst all of these standards and UK government initiatives have impacted construction processes, there are still issues with implementation of BIM resulting in inefficiencies, gaps in proper implementation and inability of the industry cultivate the value of BIM. In this context the aim of this study is to identify and provide solutions of the issues that preventing the industry of embracing BIM.

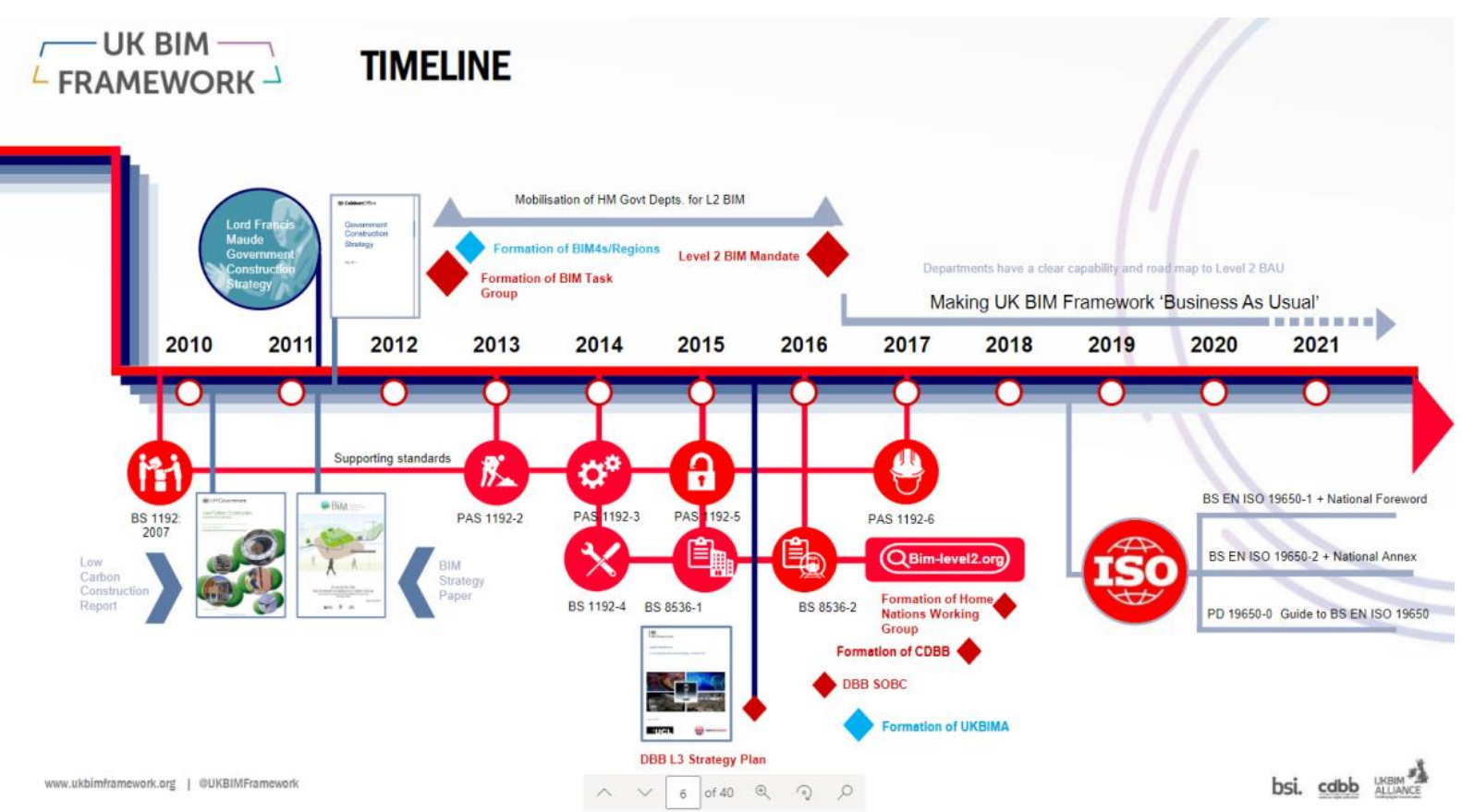

FIG. 1: UK BIM Framework Timeline (UK BIM Alliance, 2020)

In order to achieve the aim of this research project, four main objectives have been set. These are: to:

- Undertake a systematic literature review of academic and a critical review of industrial literature- This involves academic and industrial literature and reports reviews;

- Analyse, contest and support literature by undertaking a data collection exercise with a range of industry experts who are delivering construction projects and in particular infrastructure via BIM; 
- Provide a comparative analysis between data collection, academic and industrial literature in a holistic format; and

- Propose a solution focused on countering the disadvantages and inefficiencies in the adoption of BIM to the benefit of future projects.

Following on from the above, each section within this research paper is intended to build upon the knowledge attained, from both a theoretical and practical perspective respectively. A comparative analysis and summary outline a proposal for a solution framework, which is focused on increasing opportunities and efficiencies and primarily aimed at enhancing the delivery of projects via BIM. This is by reducing the preventative and restrictive gaps and inefficiencies towards gaining applied advantage.

\section{THEORETICAL DEVELOPMENT OF BIM ADOPTION IN INFRASTRUCTURE PROJECTS}

\subsection{Systematic Literature Review}

A systematic literature review (Borenstein et al., 2009) which has been undertaken as part of the design procedure, providing a 'Grounding Theory' (Glaser and Strauss, 1967), whilst also underpinning and including research methodologies, observations and conclusions ascertained from previous research (Paré et al., 2015). The Preferred Reporting Items for Systematic Reviews and Meta-Analyses (PRISMA, 2009) approach was utilised in this research to coordinate and construct the main elemental structure of the research methodology (Cohen, 2017), as well as providing a focus on the keyword string searches to filter onto appropriate literature to support the research topics and its findings (outlined within Table 1 and 2 below).

Further to the latter, exploration of relevant literature subject titles from online academic libraries (e.g. ResearchGate, Elsevier, University Library etc.) and areas by research experts was undertaken to add credibility and targeted focused to the methods presented (Hart, 2001). A selection of some of these academic areas alongside their subject focus can be found below in Table 1, with Table 2 outlining similar approaches but with focus on Industrial literature.

Table 1. Systematic Literature Review-Academic Literature Subject Focus

\begin{tabular}{|l|l|}
\hline Subject Focus/Searched Topics & Citation \\
\hline Benefits of BIM Application & Singh et al, 2010; Verkinos, 2015; Da Silva et al., 2019 \\
\hline Return on Investment & Eadie et al, 2014; Doloi, 2013; Azhar et al., 2012; Akponeware et al., 2017 \\
\hline BIM v Non- BIM Project Review & Barlish and Sullivan (2012) \\
\hline Benefits of BIM & Young et al., 2009; Chahrour et al, 2021; Bargstadt, 2015 \\
\hline Lessons Learned and Case Studies & Ustinovičius et al., 2018; Wiley et al, 2015; Highways England, 2020 \\
\hline Cultural and Behavioural Changes & Latham, 2003; Bargstadt, 2015 \\
\hline Training and Development Needs & Hore et al, 2011 \\
\hline Adoption and Implementation of BIM & Zuppa et al., 2009; Doloi, 2013; Verkinos, 2015 \\
\hline
\end{tabular}

To date there have been extensive academic and literature research techniques applied, highlighting some of the benefits of BIM such as but not limited to application within 4D construction scheduling (Da Silva et al, 2019), off site construction techniques (Verkinos, 2015) and Clash detection and avoidance (Akponeware et al, 2017; Chahrour et al, 2021).

In addition, literature from academic research teaches us that there is a benefit to applying BIM, with a ' $33 \%$ saving in cost reduction' as affirmed by Azhar et al., (2012) and thus financial benefit being realised through the utilisation of BIM for activities such as Clash Detection (Chahrour et al, 2021). Further, a key success factor at the Project Implementation Stage (from Design to Construction) stems from creating a collaborative, engaged and motivated Teams (Verkinos, 2015). This allows projects and programmes to shift their delivery teams focus on thinking more broadly about how they will deliver the Projects, with Bargstadt (2015) stating that the selection of appropriate toolsets is key to achieving better outputs via the BIM process(es). 
Table 2. Systematic Review - Industrial Literature Subject Focus

\begin{tabular}{|l|l|}
\hline Subject Focus/Searched Topics & Citation \\
\hline BIM Case Studies & Constructing Excellence, 2014 \\
\hline Measuring Collaboration & Greenwood Consultants, 2020 \\
\hline Industry Performance Reports & CITB, 2018 \\
\hline National Infrastructure Strategy & HM Government, 2020 \\
\hline BIM Implementation & UK BIM Alliance, 2020 \\
\hline Construction Reporting & McKinsey, 2017 \\
\hline
\end{tabular}

However, there is also counter evidence to suggest that benefits are very much limited in specific areas such that there is a 'lack of coherent collaborative working' (Kirby et al, 2018) with Shennan (2016) stating one reason for this is that procurement routes are 'rooted in a pre BIM world' and have an of absence modernisation and appropriation. Moreover, Aljumaiah (2020) believes that compliance of the processes and procedures specifically for BIM and 'not upheld well', and due to these reasons 'only one third of projects are delivered on time and budget'.

Furthermore, Ojo and Pye, (2020) confirm that the Construction industry is a 'complex' and dynamic in nature, which appears to be a probable reason why construction projects are difficult endeavours to deliver successfully and instil innovative methods. This is not purely in terms of or due to their volumetric quantum, but a resulting factor due to their entangled elements such as plant, people, processes, high-risk and cost (Baloi and Price, 2003). There is however a fragmentation within the AEC industry as well as reluctance to adopt and adapt to change, roles and responsibilities plus awareness and wider benefit appreciation (Singh et al, 2010).

Eadie et al (2014) also reaffirms this in agreement in that the Return On Investment (ROI) and benefits of adopting and implementing BIM are typically less likely to be realised, which may result in poor future adoption by Delivery Teams. Moreover, Barlish and Sullivan (2012) states that there is actual very little to no data available to compare 'non-BIM projects against BIM projects' which makes the former statement difficult to validate (both positively and negatively).

Moreover, Young et al., (2009) has undertaken research which outlines some of the benefits of BIM, which include a Return on Investment (ROI) can be achieved via application of BIM via experts, which can add 'three to four times' more value in terms of internal benefits in comparison to traditional production of and delivery methods.

Hardin and McCool (2015) affirm that this latter statement then results overall in 'better outcomes' for all stakeholders; be they directly or indirectly involved in the project itself and/or from lessons learned and best practice feeding back from project delivery examples. Moreover, whilst harnessing and utilising beneficial and novel approach to Project Delivery moving away from the inherent and slow-to-change inefficiencies within Construction projects. Latham (2003) outlines in the 'Five Step Approach to Behavioural Change' that it is of upmost importance that systems of measuring outcomes 'must be aligned with goals'. Further to this Latham positions himself further by stating if outcomes aren't aligned with goals then 'dysfunctional behaviours' are guaranteed. However, Zuppa et al., (2009) has also found that the adoption and more so successful implementation of BIM "is slow due to ambiguity surrounding its definition purpose and value".

Hore et al (2011) provides a 'people driven' theory behind why such assurance values aren't realised more positively by BIM, stating that the majority of the time 'Training and Education' is not 'subsidised by the Client' (and thus a cost to the Project), which typically and usually isn't delivered resulting in poor awareness and experience of how to apply theory at a delivery level. Moreover, Doloi (2013) states that another of the fundamental reason as to why time, cost and poor management of projects isn't realised is due to 'poor reporting' as well as poor planning and scheduling, which have a more direct impact on cost performance, delivery due to immeasurability. 
There is in fact further evidence from Doloi (2013) towards suggesting why Construction projects are inherently late, overbudget and are one of the most underproductive areas of work is due to 'vagueness in scope', with a further study suggesting that innovative Contractors are '50-60\%' more productive (McKinsey, 2017).

Khosrowshahi and Arayici (2012) also reaffirms that although there are standards, the barriers to adoption are 'driven by culture', which is a people led and includes humanistic behaviours and attitudes. However, Forcael et al (2020) outlines this as an 'over complex nature' but appreciates that although the Technical and Functional Requirements are important, the behavioural elements alongside BIM in terms of training People to further understand the collateral in a succinct manner who are non-specialists must also be a priority.

Moreover, Da Silva et al (2019) states that although a desire can be assigned as a goal or objective, 'lack of integration' results in a fundamental incompatibility between aspiration and realisation at the delivery phase.

\subsection{Conclusions from the Literature Review}

In summary following the systematic literature review, it appears that there are clearly stated advantages from previous research undertaken such as benefits in cost realisation and 'value of BIM' (Chahrour et al, 2021), success driven by effective collaboration and 'motivated teams' (Verkinos, 2015), as well as the selection of toolsets to align with the 'likelihood of achieving success' (Bargstadt, 2015). In addition, the value of implementation was also affirmed by Young et al. (2009) with benefits gained are ' 3 to 4 times more likely' by having skilled and qualified staff supporting project delivery via BIM.

However, equally there are also issues restricting adoption such as legacy procurement routes restricting the level of adoption (Shennan, 2016), innovation being typically hard to apply and complex (Forcael et al., 2020) and a 'lack of integration' (Da Silva et al., 2019) restricting the uptake and understanding of how BIM is to be applied practically. Moreover, common trends such as poor reporting (Doloi, 2013) is a 'contributing factor' in reducing successful delivery, with Khosrowshahi and Arayici (2012) stating this is also a factor which is 'driven by culture' and thus human centric. Further, Zuppa et al., (2009) states that there is a reduction in projects being able to gain foresight of what the realised benefits could be, leading to poor planning and a reduced ROI.

Therefore, and in conclusion to this section, a deeper analysis of both literature and data collection through the means of semi-structured interviews directly linked to infrastructure projects is needed to gain insight, improve clarity and provide wider opportunities to support and develop knowledge gained from the research findings.

\section{ANALYSING THE INFRASTRUCTURE PROJECT AUTHORITY (IPA) ANNUAL REPORT}

The IPA is required by a Government mandate originally set in 2011 (HM Government, 2011) and revised in 2021 (HM Government, 2021), to produce annual findings for all projects that form part of the Government Major Projects Portfolio (GMPP); outlining their performance, comparison against previously reports, confidence factors in terms of delivering to scope and areas for future development respectively.

These annual IPA reports essentially split UK Major Projects into four Departmental areas which include Infrastructure and Construction, Military Capability, Government Transformation and Service Delivery and Information and Communications Technology. The GMPP areas are summarised and further outlined below in Figure 2 for 2019-2020, which amount to $£ 448$ bn of value aligning to Whole Life Costs (WLC).

Another key function of the IPA is to provide governance, assurance, and guidance to better inform Project Management and Delivery across their portfolio, as projects progress throughout their lifecycle, but to also stakeholders and interested parties of best practice, guidance and lessons learned. Through the use of tools such as a Delivery Confidence Assessments (DCA), the likelihood of success factors are evaluated on a Red, Amber, Green (RAG) traffic light system methodology, with appropriate steer and support to inform so that turnaround is more likely if negative elements are evidenced, and more positively best practice shared to the wider GMPP.

Focusing back to the evaluation of the report itself, one of the fundamental roles of the IPA to its 'commitment towards to improving Project Delivery across Government' with its 'three P's'. These founding principles are:

1. People (need for the skills, competence and behaviours);

2. Principles (the clarity and basic understanding); and

3. Performance (driving a step change in performance together with industry). 


\section{Figure 1: Summary of the 2019-20 GMPP}

\begin{tabular}{|c|c|c|c|}
\hline & $\begin{array}{l}\text { Government Major } \\
\text { Projects Portfolio }\end{array}$ & $\begin{array}{l}125 \\
\text { projects }\end{array}$ & $\begin{array}{l}\text { \&448bn } \\
\text { Whole Life Cost }\end{array}$ \\
\hline \multicolumn{4}{|c|}{ This comprises: } \\
\hline & Infrastructure and Construction & $\begin{array}{l}34 \\
\text { projects }\end{array}$ & $\begin{array}{l}\text { £214bn } \\
\text { Whole Life Cost }\end{array}$ \\
\hline & $\begin{array}{l}\text { Government Transformation } \\
\text { and Service Delivery }\end{array}$ & $\begin{array}{l}34 \\
\text { projects }\end{array}$ & $\begin{array}{l}\text { £64bn } \\
\text { Whole Life Cost }\end{array}$ \\
\hline & Military Capability & $\begin{array}{l}30 \\
\text { projects }\end{array}$ & $\begin{array}{l}£ 162 \text { bn } \\
\text { Whole Life Cost }\end{array}$ \\
\hline & $\begin{array}{l}\text { Information and Communications } \\
\text { Technology (ICT) }\end{array}$ & 27 & $\begin{array}{l}\text { £8bn } \\
\text { Whole Life Cost }\end{array}$ \\
\hline
\end{tabular}

1 The Government's GMPP Data Transparency Policy covers Whole Life Cost, Delivery Confidence Assessment, and project end dates. It does not include project benefits. See Annex for further information.

FIG. 2: Extract from the IPA 2019-2020 Major Projects Review Report (IPA, 2020)

The IPA's mantra is to focus efforts on improving the successful delivery of Major Projects, reporting directly into Government at a portfolio level. However, despite their being a consensus of a proven track record of delivering projects against the Cabinets priorities and requirements, Infrastructure and Construction projects are shown within as being still inherently late and overbudget, with complexities having wider impacts on Social, Economic and Environmental areas respectively. Projects themselves receive independent scrutiny, assurance support/services plus guidance from IPA however as stated there are significant fundamental problems with Project Delivery that typically result in negative outcomes, such as overspend, late decision making, and programme overrun.

\subsection{Benchmarking System}

Since 2013 at the inception of the mandate and thus the analysis of projects via the production of annual reporting, the IPA has undertaken DCA's for all projects which are part of the GMPP and measured via a simple yet effective Red, Amber, Green (RAG) rating system.

The IPA reports are evaluated and summarised within this section of the paper. Coincidentally, these findings, ranging back seven years sit alongside the implementation and transition of the UK BIM Mandate (HM Government, 2012) as part of the UK BIM Framework (UK BIM Alliance, 2020).

Each project has an evaluation undertaken at key decision points or 'gates' which focus at specific intervals on the likelihood of a Project being able to achieve as a minimum timely delivery, benchmarked costings and the least disruption as possible away from the Project scope. Moreover, the ratings are based on the qualitative RAG conclusion with interim points i.e. Amber/Red and Amber/Green amounting to 5 areas of measurements across the 125 projects for the year 2019-2020.

To better inform and describe the benchmarking criterion behind the RAG system, Annex A within the appendices of the IPA report explains further in plain language the rationale in that 'The DCA is the IPA's evaluation of a project's likelihood of achieving its aims and objectives and doing so on time and on budget' (IPA, 2020). This is further summarised below in Table 3 and is used alongside the evaluation of each project scoring metric. 
Table 3. Explanation of DCA Colour Ratings (Redrawn from IPA, 2020)

\begin{tabular}{|l|l|}
\hline IPA Colour Rating & Description \\
\hline Green & $\begin{array}{l}\text { Successful delivery of the project on time, budget and quality appears highly likely and there are } \\
\text { no major outstanding issues that at this stage appear to threaten delivery significantly. }\end{array}$ \\
\hline Amber/Green & $\begin{array}{l}\text { Successful delivery appears probable; however, constant attention will be needed to ensure risks } \\
\text { do not materialise into major issues threatening delivery. }\end{array}$ \\
\hline Amber & $\begin{array}{l}\text { Successful delivery appears feasible but significant issues already exist, requiring management } \\
\text { attention. These appear resolvable at this stage and, if addressed promptly, should not present a } \\
\text { cost/schedule overrun. }\end{array}$ \\
\hline Amber/Red & $\begin{array}{l}\text { Successful delivery of the project is in doubt, with major risks or issues apparent in a number of } \\
\text { key areas. Urgent action is needed to address these problems and/or assess whether resolution is } \\
\text { feasible. }\end{array}$ \\
\hline Red & $\begin{array}{l}\text { Successful delivery of the project appears to be unachievable. There are major issues with project } \\
\text { definition, schedule, budget, quality and/or benefits delivery, which at this stage do not appear to } \\
\text { be manageable or resolvable. The project may need re-scoping and/or its overall viability } \\
\text { reassessed. }\end{array}$ \\
\hline Reset & A significant change to a project's baseline which involves a business case refresh or change. \\
\hline Exempt & $\begin{array}{l}\text { Data can be exempt from publication under exceptional circumstances and in accordance with } \\
\text { Freedom of Information requirements - i.e. national security }\end{array}$ \\
\hline
\end{tabular}

\subsection{Analysis of Project Confidence Data}

Figure 3 below provides background and historic data outlining the trends and typical themes of Project measurements over the yearly periods from 2013 to 2019 inclusively. It combines and summarises the DCA's measured confidence for all projects undertaken on the GMPP list, spanning back over seven years, whilst following the 2012 discussion on and introduction to a proposed BIM mandate (UK Government Construction Strategy, 2011).

FIG. 3: DC analysis 2013-2020 (IPA Major Projects Review, 2020)

\begin{tabular}{|c|c|c|c|c|c|c|}
\hline \multicolumn{7}{|c|}{ Figure 6: DCA Analysis 2013-2020 } \\
\hline AR 2013 & 8 & 23 & 58 & 49 & & $21 \quad 191$ \\
\hline AR 2014 & 4 & 37 & 63 & 54 & 17 & $15 \quad 8$ \\
\hline AR 2015 & 8 & 40 & 64 & 44 & 28 & 4188 \\
\hline AR 2016 & 6 & 38 & 55 & \begin{tabular}{l|lll}
10 & 5 & 143
\end{tabular} & & \\
\hline AR 2017 & 4 & 34 & 71 & \begin{tabular}{l|l|l|l}
23 & 5 & 5 & 143
\end{tabular} & & \\
\hline AR 2018 & 8 & 38 & 59 & $22 \quad 24133$ & & \\
\hline AR 2019 & 4 & 38 & 68 & \begin{tabular}{l|l}
18 & 4 \\
3 & 133
\end{tabular} & & \\
\hline AR 2020 & 11 & 32 & 59 & $18 \quad 32125$ & & \\
\hline
\end{tabular}

Further to the historic reflection/year-on-year breakdown of DCA evaluations, Figure 4 below focuses solely on the 2019-2020 'confidence ratings' for the total number of projects across the four categories namely Infrastructure and Construction, Government Transformation and Service Delivery, Military Capability and ICT. Projects within these categories total 125 .

Analysing the data further, the Infrastructure and Construction Department is joint top in terms of the total number of projects (a total of 34) alongside Government Transformation and Service Delivery. However, in terms of Whole Life Cost (WLC), Infrastructure and Construction has a much larger average value of $£ 6.3 \mathrm{bn}$, only being topped by Military Capability which is measured at $£ 6.5 b n$ and has 4 less projects ( 30 projects). Furthermore, the Infrastructure and Construction Department has direct synergies and links into the requirement to deliver against a set of defined criteria instructed as Collaborative BIM via the UK Government Construction Strategy (HM Government, 2012) BIM Mandate. Naturally this is of particular interest in spotting trends linked to the adoption and implementation of BIM and thus benefits gained in quantitative and qualitative measures. 


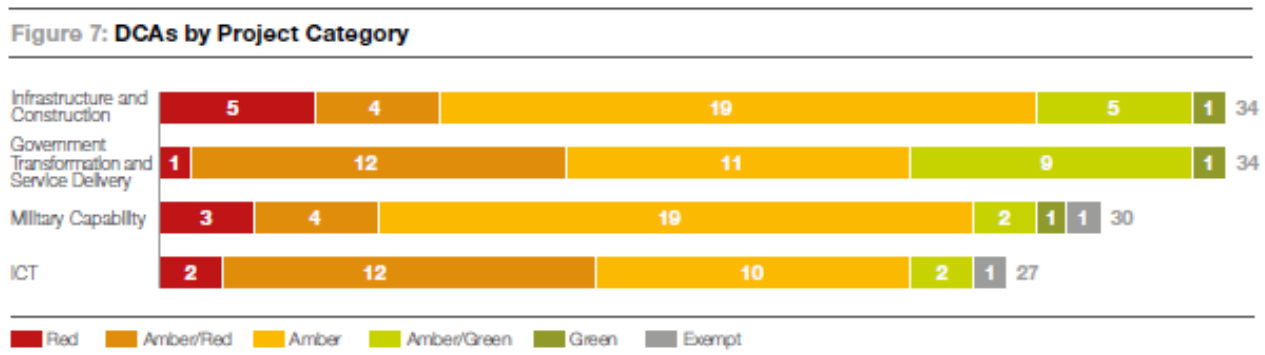

FIG. 4: DCA's by Project Category (IPA Major Projects Review Report, 2020)

The total WLC in 2020 for the 125 projects analysed and evaluated is stated as $£ 448 \mathrm{bn}$, which is an increase of $£ 6$ bn from the previous 2019 appraisal report. Further, the Infrastructure and Construction Department has an average Project length of 12 years, which is 5 years behind in respect to Military Capability sector, but is relatively long in duration compared to others, such as the Information and Communication Technology sector.

\subsection{Infrastructure and Construction Sector- Analysis}

Looking specifically at, as set out at the beginning of this paper, the project category 'Infrastructure and Construction' for the year 2019-2020, there is a disproportionately high percentage of projects that are either in the Red, Amber/Red or Amber. Furthermore, $45 \%$ of Infrastructure and Construction projects fall directly into the Red area when averaged across the four categories. Extrapolating and investing further into the 'Project Confidence' metrics across the five DCA ratings for the year 2019-2020, percentages are tabled alongside the categorises of confidence below in Table 4.

Table 4. Summary of DCA for Infrastructure and Construction; Project Confidence

\begin{tabular}{|l|l|l|}
\hline DCA Status & \# of Projects & Percentage (\%) \\
\hline Red & 5 & 14.7 \\
\hline Amber/Red & 4 & 11.8 \\
\hline Amber & 19 & 55.9 \\
\hline Amber/Green & 5 & 14.7 \\
\hline Green & 1 & 2.9 \\
\hline Total & 34 & 100 \\
\hline
\end{tabular}

Although there is evidence presented within the report that shows that $27 \%$ of projects have improved in their DCA measure between 2019 and 2020 as well as being better aligned for successful delivery, there is a significant risk that the rather top-heavy measurement of $73 \%$ of projects will fail to deliver in confidence against their committed scope (time, budget etc). This negative appraisal is also reflected as an increasing trend when looking backwards in time at the number of 'Green' confidence ratings, which are decreasing in number since the reports were initially produced in 2013 (refer to Figure 3 above).

\section{METHODOLOGY OF DATA COLLECTION FROM CONSTRUCTION EXPERTS}

\subsection{Design and Procedure}

To gain both a wider and an enhanced understanding regarding the adoption of BIM in Design and Construction from both academic and industry perspectives combined, a framework was developed. This framework has a strategic approach towards data collection, understanding core themes and evidence attainment to essentially the bridge gap between the theory and real-world application, which was investigated further via semi-structured interviews. 
Following the above, several methodologies were selected for use within this paper to create a comparative analysis alongside 'experiential knowledge' to gain a more holistic view across various rich datasets (Maxwell, 2005), forming part of the data gathering exercise.

The core underpinning methodologies selected and applied as part of the study design were as follows:

- $\quad$ Systematic Literature Review (Borenstein et al., 2009);

- $\quad$ Semi Structured Interviews (Bernard, 1988); and

- $\quad$ Critical Review (Baumeister and Leory, 1997).

These methods were practically applied to assist in analysing, comparing and drawing on conclusions from a range of theories, opinions and observations, with no disproportionate bias towards one method over an alternative (Paré et al., 2015). Further, this methodology allowed an in-depth exploration as part of the 'Grounded Theory' (Glaser and Strauss, 1967) of academic and industrial literature by systematically focusing and selecting targeted data. The former was used alongside semi-structured interviews (Bernard, 1988), as well as the reported project measures of BIM implementation via critically reviewing supplementary datasets.
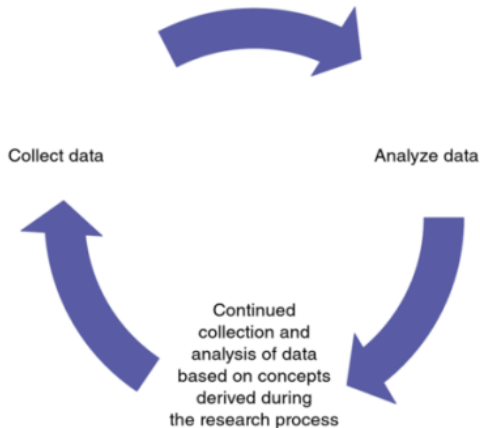

FIG. 5: Interrelationship between data collection and analysis (Corbin and Straus, 2008)

Further, 'Thematic Analysis' (Houlton, 1973) was used throughout the structure of the methodology as an overarching approach to identifying themes and patterns and progressing to review and distinguish data collection from a qualitative perspective. Braun \& Clarke (2013) state that this approach encompasses and instils a 'distinctive method with a clearly outlined set of procedures'.

Figure 6 below visually outlines the described process and procedure discussed above, whilst also highlighting the feedback loop between evidence found at the data collection stage linking back into possible addition of exploration at the literature review stage, as well as forwards towards consolidating and capturing results and concluding remarks from evidence ascertained.

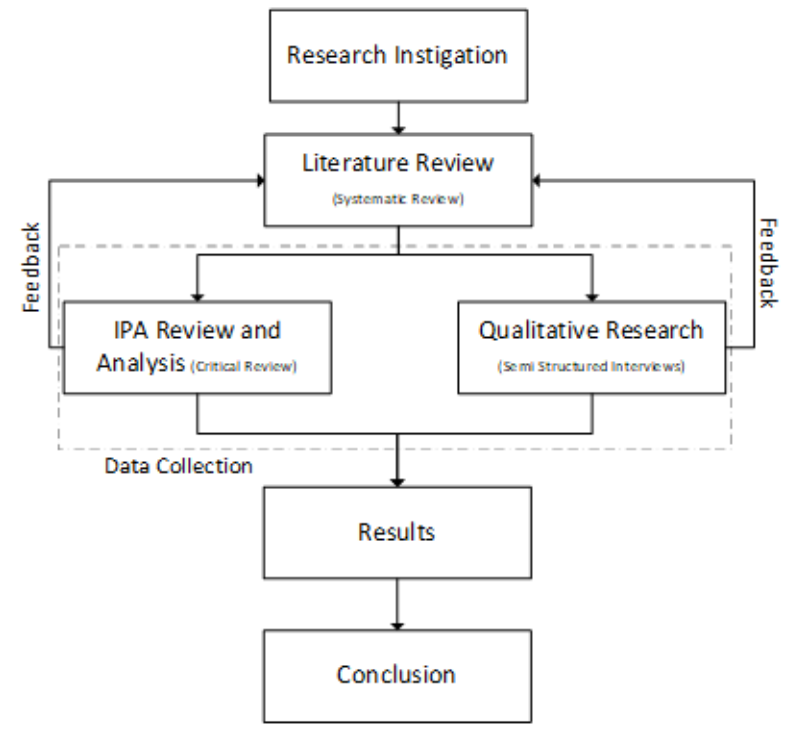

FIG. 6: Block diagram of data collection incorporation 
Finally, the conclusion section of this paper synthesises the data, provides a conclusive insight into the emerged findings, trends and relationships, post hoc analysis, opportunities and observations (Braun and Clarke, 2013), as well as outlining a framework solution aimed at identifying and countering the issues faced.

\subsubsection{Semi-Structured Interviews}

The semi-structured interviews' core purpose was primarily aimed at adding a further insight through data collection of applied BIM at the execution stage, and to also compare and analyse data collected against academic and industrial literature, and thus draw more rounded conclusions.

Following on from the above, a range of 'descriptive, exploratory and interpretive' (Gray, 2009) questions were designed as part of the qualitative research study to enable data capture from multiple sources and methods. Denzin (1989) states that this is to bolster the feedback received from a range of 'core' respondents and to apply focus on 'reliability' of the answers received. This means that despite who the interviewer is, answers have higher likelihood in being consistent if designed using the 'triangulation' methodology, adding to, and increasing the validity of the data collection (Denzin, 1989).

These questions which can be found with Appendix A of this report, encompass, and add to the framework of issues and opportunities, utilising the 'pragmatist' methodology (Rossman and Wilson, 1985). The questions developed focus on understanding further areas such as the benefits of BIM at the application stage, the impact of standardisation (and subsequent updates), how success is measured, how goals and objectives are set and how people are impacted by the adoption and implemented of BIM. In addition, this is also alongside responder feedback on the UK Government reporting of Project confidence via industrial literature and a free input question with the interviewer playing an 'Observer' role (Hart, 2001).

Individuals were purposefully selected who were industry facing with a minimum of 10 years' experience across project delivery and construction via BIM, with a bias to both practical application and fundamental understanding of theory but also with 'critical similarities' of the subject focal point (DiCicco-Bloom and Crabtree, 2006); in this case the adoption and implementation of BIM. This was to ensure that the design of the applied methodology complimented and added to the 'Grounded Theory' (Glaser and Strauss, 1967), which Strauss and Corbin (1994) state uses 'the interplay between analysis and data collection to produce theory'.

Furthermore, to ensure that an 'underpowered study' was not inadvertently designed and reflected in the data collection and analysis (Fraley and Vazire, 2014), the sample size was slightly dominant towards construction, but also included a connection with design experts too (36.3\% Design, 63.6\% Construction). This was intended to not limit the data collection and so that the evaluations made reduced the likelihood of bias towards a specific stage or stakeholder as part of the study.

In addition, Table 5 below has been provided to show the diverse range of interviewee's who were invited as part of the semi-structured interviews, focused on gaining further insight into areas of success, negative impacts and highlight potentially new areas for reaffirming evidence and/or providing a platform to explore new areas (complimenting the literature review). Diversity is typically difficult to incorporate into such data collection activities (Grey, 2009). However, due to the strategy and approach taken the group of individuals invited to interview purposefully have diversity both in terms of their experience, accountability and within their operation roles.

Table 5. Summary of DCA for Infrastructure and Construction; Project Confidence

\begin{tabular}{|l|l|l|}
\hline Function & Role & Date of the Interview \\
\hline Construction & BIM Infrastructure Manager & $09-02-21$ \\
\hline Construction & Regional Director & $18-01-21$ \\
\hline Construction & BIM Lead & $19-01-21$ \\
\hline Construction & Project Director & $11-02-21$ \\
\hline Construction & Regional Chief Engineer & $23-02-21$ \\
\hline Design & BIM Coordinator & $23-02-21$ \\
\hline Construction & Senior Project Manager & $26-01-21$ \\
\hline Design & BIM Designer & $12-02-21$ \\
\hline Design & Operations Director & $10-02-21$ \\
\hline
\end{tabular}




\begin{tabular}{|l|l|l|}
\hline Function & Role & Date of the Interview \\
\hline Design & BIM Manager & $10-02-21$ \\
\hline Construction & Construction Director & $16-02-21$ \\
\hline
\end{tabular}

The interviews were undertaken over a duration between 30-45 minutes, against ten predetermined questions, with one final 'open question' for participants to respond to (adding further evidence if they think it will add value) this enables a more in-depth account of feelings, evidence and responses (Chilban, 1996), as well as a facilitating an 'observational' role in regard to the open response final question.

\subsubsection{Critical Review}

A critical review of core industrial literature, in both qualitative and quantitative forms was undertaken as part of the design of the analysis to 'provide a critical evaluation and interpretive analysis' (Baumeister and Leary, 1997). This method facilitates and enables dissection, interpretation and critical evaluations of literature which can be undertaken without any intentional bias (Paré et al., 2015).

This review, which was focused directly on the Infrastructure Projects Authority (IPA) Major Project Annual Report 2019-2020 (IPA, 2020), was undertaken to extract core project Delivery 'Confidence' data from the industry focused report to further understand and analyse current figures and data comparatively against other methods, in critical yet systematic manner (Hart, 2001). This analysis and results are found below with the 'Results' section.

This critical analysis approach of the subject allows further determination and dissemination of the success factors and benefits as well as the inefficiencies, disadvantages and ultimately how the application of BIM is being reflected quantitatively in the Key Performance Indicators (KPI's), as reported within the UK Government report (IPA, 2020).

\section{RESULTS}

The sections which follow are divided into the two predominant areas of analysis, with their intended focus on understanding further the inherent issues of BIM adoption within infrastructure construction projects.

1) IPA Annual Report Examination; and

2) Data Collection via Semi-Structured Interviews.

\subsection{Data Collection- Semi-Structured Interviews}

As defined in the methodology section above, to gain a holistic view of the applied status of BIM implementation across academic and industrial literature, thought provoking questions were designed as outlined within Appendix A and themes summarised in Table 6 below as part of the data collection process.

Table 6. Interview Themes and Descriptions

\begin{tabular}{|l|l|}
\hline Themes Identified in the Interviews & Rationale \\
\hline BIM Standards, Methods and Procedures & Insight into standardised methodology benefits \\
\hline Productivity and Project Confidence Factors & Exploration of extending opportunities \\
\hline Benefits, Desires, and Inefficiencies of BIM Implementation & Ascertaining the drivers and blockers of BIM \\
\hline Role Specific Gain and Benefit from BIM & Understanding benefits to people \\
\hline Measuring Successful Adoption & Learning from data capture \\
\hline Reviewing Goal Achievements & Exploration of how objectives are realised \\
\hline Open Question (Free Input) & Opportunity to act as an observer \\
\hline
\end{tabular}


The questions, which form part of the research methodology, were designed to be placed directly to industry experts who are practically applying BIM at the Design and Construction stages, to gain their thoughts, comments, knowledge and insights on the success, failures, advantages and misconceptions of BIM in terms of adoption and implementation.

\subsubsection{BIM Standards, Methods and Procedures}

All eleven of the respondents agreed that the standards, methods, and procedures were important in creating a common approach to delivery of projects via BIM methodologies, and specifically over the past 5 years they have added a "huge benefit" and more are "very important in methodology" in alignment of the requirements of BIM. However, due to the vast amount of literature and transfer from BS to PAS to ISO several respondents added that some benefit has been lost and a "lack of understanding of the requirements" at a practical level has reduced the attraction and advantage that BIM can offer. Furthermore, one person responded with a comment stating that although they understand the rationale behind the suite of standards they did feel that most of the responses at the tender and even delivery stage was "lip service to clients", that clients "didn't really know what they were looking for" with BIM adoption and implementation other than "nice fluffy 3D models" which was also reaffirmed by others.

In addition, another commented that implementation is "Definitely going in the right direction, but I think that there's problems lies in the skills" adding a further statement that they think the success of standardisation is limited by "people understanding technology and how to them".

\subsubsection{Lessons Learned and Benefits}

In regard to measuring and sharing lessons learned and benefits of BIM, general agreement from all respondents was that this was not done sufficiently, that it was "difficult to put a number of the benefits" and is generally more because of this its "an issue, and I don't think we have a good measurement tools". In addition, it was typically relayed by several statements that people in industry could "tell you a story about the benefits, but not measure them quantifiably" which meant communicating either through conversations or visual outputs of case studies. One respondent advised that a difficulty was due to the benefits being harder to measure unless "every function buys into it" and went further stating that "not all parties are delivering via the BIM requirements", which was also a common theme reproduced by respondents.

\subsubsection{Productivity and Project Confidence Factors}

Directly related to the IPA report evidencing year on year a reduction in project confidence of being delivered on time, on budget and with reduced disruption one respondent believed this was because the Client "wants BIM because its mandated" but what they actually want is to simply "deliver to programme, within budget and not have any defects". It was stated by five respondents that "objective focus" which was described as reviewing, agreeing and positioning stakeholders towards what is required from BIM alongside a reduction of specific targeted goals via BIM was a possible reason why there was inefficiency and lack of return and stunt in advancements made (as evidenced within the IPA reporting). Insightfully, a respondent stated that "scatter brain at the last $10 \%$ of a project" is where the inefficiencies come from at the Construction stage, regardless is the method for delivery is BIM or not with another, adding that "the tangible benefits where you make the cost savings at the end are not realised, because at the end [BIM, Data Exchanged and Digital Methodologies] are not being used". Another added that a potential and fundamental reason was that the focus on reducing cost, improving punctuality and adding value was "a fantastic dream that they tried to sell to everyone" via the BIM mandate, but there are "many external factors that impact the lifecycle of a project".

\subsubsection{Benefits, Desires and Inefficiencies of BIM Implementation}

When faced with delivering and/or implementing BIM on a project, a common theme in terms of desires was that they wanted to "add value" to their delivery via BIM processes and digital engineering but felt like the understanding of "what BIM is" and lack of clarifying what BIM is for the project "despite the BEP, core documents etc" was a reason for the inefficiencies. One respondent passionately stated that "BIM is not just a 3D model", and others believed that "the most important thing is all about data" when actually it should be about focus and using these tools and methods to achieve the goal or objective. Further, it was advised by another respondent that a pain point was getting "data from the design model across to the construction model", which at the moment required manual intervention and 'manufacturing models' were different to the former, which is an ongoing "pain 
and inefficiency", with missing elements included within the "RIBA (Royal Institute of British Architects" frameworks).

Another respondent advised that applying BIM is a "massive step change onto their project(s)" adding further that it" takes time and when you are on a project with tight timescales the last thing anything wants to do is take a step back and try to learn how to use something".

In terms of understanding of what BIM is fundamentally, the consensus was that there is still a lack of understanding by most stakeholders at the application stage ranging from "Clients who want $100 \%$ BIM" but then ask "what's an EIR", to sub-contractors who say "they are just supplying what you require". Further, those who have a greater awareness and understanding are the people who use specific elements to "benefit" their outputs and roles. Benefits are realised so that it "becomes normal" with one respondent confirming this by stating that adoption "of course takes time and you'd almost consider this as part of a transition period".

Expanding further on the latter paragraph, benefits from respondents were linked to "avoidance of rework and defects" with one respondent stating they believe defects have reduced in buildings from " $5 \%$ to $3 \%$ " because of targeted BIM application. However, a counter statement was that "other benefits can come, but it's a big investment" as well as "a lot of the competition aren't making the same investment", which meant some of the supply chain weren't disincentivised by investment needed (time, cost and productivity impacts).

Further, another individual replied that they believed the key to successful understanding was by putting "Trust in the people and training them I the same way", so that "awareness is set" and therefore much more likely to succeed.

\subsubsection{Role Specific Gain and Benefit from BIM}

Regarding whom gains most benefit from BIM adoption the consensus was split, however one comment was that "Designers and Contractors benefit most", as better accuracy will result in additional projects and improved collaboration between Contractors. Another stated that if the goals and approach to why BIM is being applied is agreed then "all can benefit from building safely and efficiently" as well as another proposing that the end user and client will have most benefit as they know "what he's getting" linked to "what he's going to use it for" which links into downstream use of "3D models that can be constructed and maintained from". Other respondents however countered this opinion, stating that the "client will have most benefit" but adding further this can be true "but it's got to be an educated client". Further, another stated that "at the moment $90 \%$ of clients can't see and don't get the benefits, and most are forced into BIM" due to a lack of understanding of "what it means". This is translates into "poor governance and adoption" and is more often misunderstood by "middle to senior to client" management levels.

In addition, there was consensus between $50 \%$ of respondents that those who do understand and "get BIM" are the "younger engineers and designers" and more so the "guys on the ground", but there was a "real detachment the more you go higher" adding to the previous respondents thoughts on hierarchy disconnect. It was believed this is the case due to "management thinking that it's all about technology, models and software".

Another respondent added that effectively the gain should be initially for the "Designers and Contractors" but more so the ultimate gain should be "to the UK Taxpayer" via the appropriate delivery of projects via BIM. Further, this person added that they would "hope that projects don't cost as much [if BIM is applied correctly], so it creates enough efficiencies that the public purse is the one that benefits".

\subsubsection{Measuring Successful Adoption}

A very common and consistent theme in relation to measuring the success of BIM adoption and implementation was that it is "difficult to record it" in a tangible and quantitative way, with one respondent advising that "we are definitely seeing less hours against rework" but this is coupled with more effort needed in BEP production, modelling inputs and some "general inefficiencies" (due to lack of clarity). Furthermore, a "BIM v Non-BIM" assessment and measurement of the benefits in relation to traditional methods has "not been undertaken across sectors", to confirm advantages and disadvantages across all areas of implementation.

In addition, a respondent stated that the "quantifiable element that PM's really care about is hours spent and I don't think we really go into detail previously how many hours we spend currently doing something" with BIM certainly demanding "more time for management of tasks, CDEs and so on". This is also linked to difficulties in having less of a "justification" for opting for and implementing BIM and more so being able to "track the benefits". 
However, one Highways and Civil Engineering interviewee stated that a reason for this was that "we are not doing the same thing day in day out" therefore making it difficult to measure the variables, with another stating "that is the problem, it isn't measured is it". Moreover, another input in response to the question of measuring the success only one respondent commented that they are "measuring the time spent on model production, issue resolution, change mechanisms, KPI's etc" on a "weekly basis", which then looks at comparative data of similar tasks on previous occasions to spot trends and efficiencies from "taking ownership of the model through to the handover at the end".

Another added that they "aren't aware of qualitative or quantitative data being produced" including "appropriate KPI's" to support measures and management, with another stating that although this is largely true "large scale frameworks and alliances should be doing that across 10 year commissions having all those metrics an assessing them".

Furthermore, one comment was made that success is simply measured when BIM is "done in the way that when the Client is happy" the company is awarded additional works. Others similarly added to this point separately and stated that they didn't "think its measured at all, and that's why there is so much confusion around BIM" and that there possibly is "something missing in the middle", to gain clarity of the required measures.

\subsubsection{Reviewing Goal Achievements}

In terms of reviewing goals for the application of BIM alongside measuring the success on achieving these objectives, one respondent commented that these have been "done on a central level [for commercial reasons] and not at a project level" with another stating that at this stage "we're still in a fact-finding element" of measuring success and achieving objectives. Moreover, another respondent commented that although the goals for them were "quite simply to get projects delivering digitally" with a reference to an "Engineering Excellence" program across a business which focuses on sharing "best practice and innovations" across an intranet with success being shared to other colleagues most often via "a conversation as it always is about people".

Commonalities are made from other respondents with responses such as although goals are set and achieved, they could be perceived as "empty goals" in that "they are not defined" and are typically an "opened ended empty list of "things". Additional responses were simply put, in that measuring, reviewing and acting upon goals set "isn't measured", and that this area was lacking maturity and that there wasn't "any measure in designer organisations" but this can only be done on at a similar sector based project level due to the fact across sectors and disciplines "it is so very different".

\subsubsection{Open Question (Free Input)}

In terms of the free input question, a comment was made that there is heightened complexity now with additional systems and it "just seems at times they're so complicated, difficult to use and we are losing value in them". It was also stated that the development of BIM requirements has meant that teams have to "bring in a load of specialists" to digest and translate when all that the project is trying to do is "make the lives easier and more efficient". This is countered by the initial intent of BIM by "reducing the value".

Further, the responder added that once the above happens staff "don't use tools correctly and it [BIM] goes back to lip service".

Another respondent commented that a problem with "parts of the BIM process" is when people don't "put documentation on place" linked to creating clarity, which means you have to "unstitch" on ad-hoc basis which can lead to inefficiencies and rework.

In addition, similar comments were made by several respondents stating that "The gap between the Construction and Design is a must to address and to make sure everyone is and are in the loop" which is linked to "education and awareness" and the appropriation at the application stage of BIM.

Finally, a respondent added a final statement with some thought provoking questions such as "How do we stop it [BIM] being a computer game pull it back to the reality of what we actually do in the ground and make it efficient", because "You're probably getting $80 / 20 ; 80 \%$ benefit for $20 \%$ of the aspect and to get the last $20 \%$ you're probably footing $90 \%$ of the cost.. is that really where we want to be... maybe not?". 


\subsubsection{Additional Analysis}

The figures which follow highlight and summarise repetitive words that each respondent used throughout the interview process, with those linked topics and words shown within Figure 7, and those that were replicated more boldly dominant as shown within Figure 8.

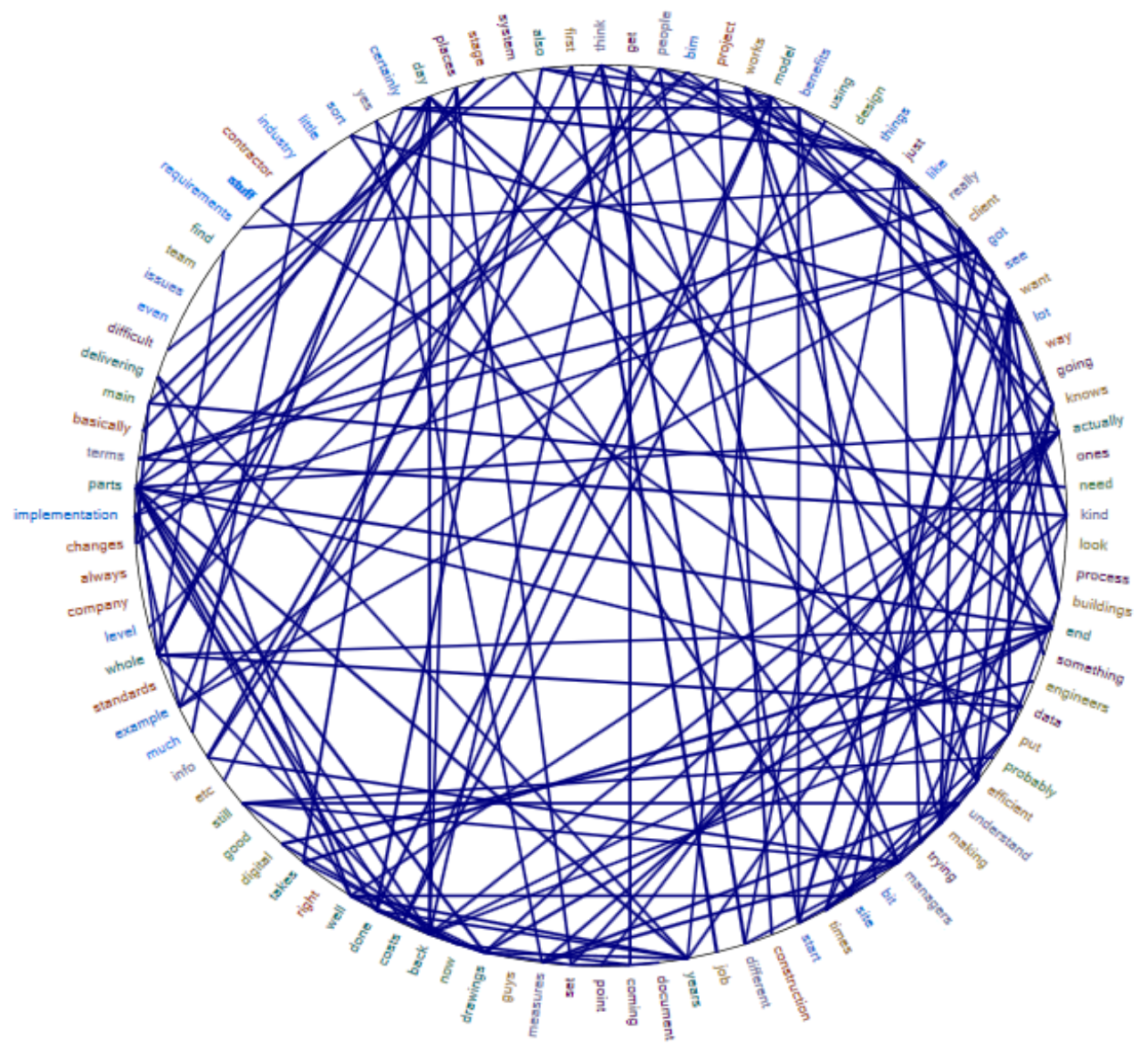

FIG. 7: Linked words and topics post interview analysis (100 most frequently used words)

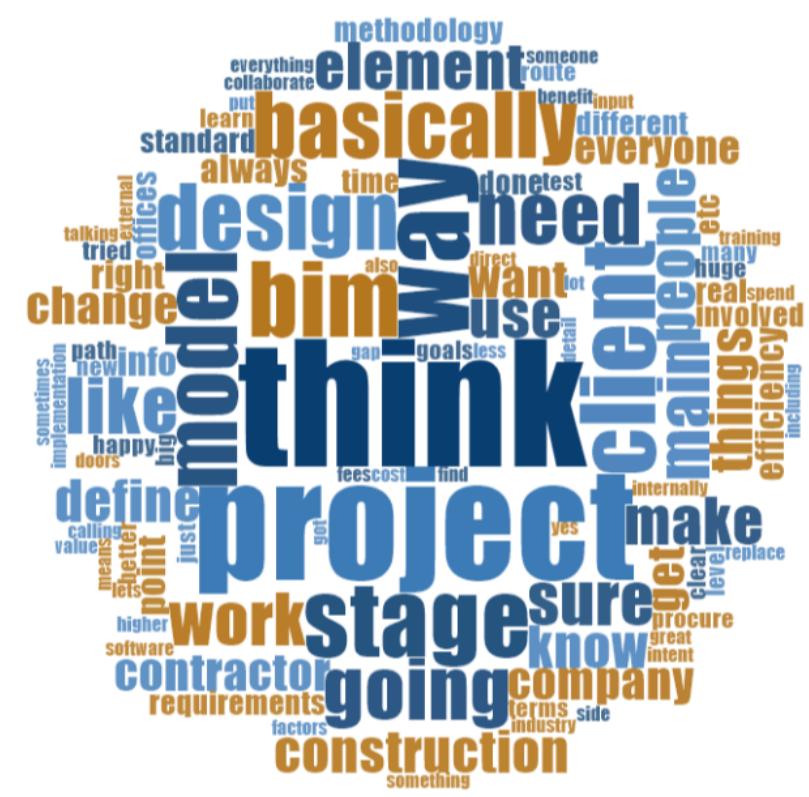

FIG. 8: Dominant words and topics post interview analysis 
It is evidenced visually above that common words such as 'project, think and client' were used most often, with dominantly yet equal weighted trends of 'design, people and construction' received most at the data collection stage from industry experts.

What this shows is that the issues with adoption from data collection from infrastructure construction facing experts at the interview stage appear to be people centric and not directly restricted because of or by the technologies available to BIM projects. In addition, the proportionate collation of words used shows in Figure 8 that 'requirements' and 'everyone' are also linked and common to gaining benefits from BIM such as collaboration, implementing digital strategies and delivering core outputs to the clients information requirements. This is also reaffirmed within the former sections in that these specific points are very important in removing the obstacles and are relevant in respect to issues facing poor adoption techniques.

\section{SUMMARY AND CONCLUSION}

\subsection{Discussion}

Evidence and thus findings within this research show that although there is a suite of developing standards from BS to PAS to ISO, positioning projects compliantly alongside the UK BIM Framework requirements, there are inherent inefficiencies to the successful adoption and implementation of BIM. These inefficiencies are directly reflected in industrial reporting, notably within the IPA annual reports stating $14.7 \%$ of projects have a red (low) and $2.9 \%$ have a green (high) confidence rating for 2019-2020.

In addition, these difficulties and inefficiencies have been extracted from the semi-structured interviews which highlight a reduction in detailed goal setting and objective focus on what BIM could facilitate and enable, through clear line of sight to seek objective focus. Further, a lack of qualitative and quantitative measures available to stakeholders to assist in the measurement and management of BIM delivery as the project is being developed and delivered is not typically available for BIM i.e. none of the respondents were aware of a system or convention available. Typically, when projects are measured this is undertaken either through generic KPI's and usually close out stage, when it is often too late to gain a benefit, make sufficient changes if objectives are heading off track or educate staff in some of the advantages that may increase the value of BIM and elements therein. Again, evidence from interviewees stated that they weren't aware of a commonly available system or method for capturing BIM advancements, goals or outputs at the application stages across the project lifecycle.

All respondents from industry believe the standardisation and protocols are required and increase benefit, which have largely helped in advancing from pre-BIM to current BIM but at the application stages. However, it is also believed because of the "complex" languages and reduced focus on the applicable intent, there are some poor methodologies and fragmentation incurred. These are associated specifically to being able to utilise BIM as a mechanism to deliver against clearly defined outcomes and delivering goals with a finite objective focus.

\subsection{Synthesis of Results}

This section provides a cross examination and draws a comparative analysis and synthesis on the findings and observations from the three main areas within the research methodology (see Figure 2 above), focused on the adoption issues within infrastructure construction projects.

Digital tools, methodologies and processes have been regarded as bringing a ' $20 \%$ saving' at the Construction stage via 'collaborative 3D BIM' (HM Government, 2011), which has been realised at a case study level by Chahrour et al (2020), focusing on elements such as clash detection and achievable financial benefits through appropriate capturing and measurement of issues faced, pre realisation. However, industry experts responded unanimously that although standardisation paired with technological advancements was a core requirement and an enabler to creating efficiencies via BIM, they feel the "lack of objective focus" means that the application doesn't solely reap benefits when applied wholesale across the project lifecycle. Moreover, nor is it measured sufficiently between "BIM v Non-BIM" and a lack of ROI justification means BIM is perceived as "just a cost" and thus reflected in update.

Kirby-Turner and Whittington (2018) state that a reason for this is gained by 'potential confusion' stemming from a vast range of standards, protocols and guidance respectively. Further, education targeted towards more senior levels within industry detailing what BIM is at a project level is compacted, which results in a reduced 
understanding at a management level and lack of prioritisation on specific goals towards the application of BIM (and thus not being agreed and set, measured and reviewed accordingly). This reduces the value through "lack of appropriation", with consensus believing for data collection that BIM is simply perceived in most cases as a "flashy 3D modelling" and similar outputs. Zuppa et al (2009) states that for the successful adoption and to "enable the successes' education, role and awareness must be a priority and there was evidence from the semi-structured interviews that this is missing again at the execution stage of BIM projects.

Further, data collection from the interview stage suggests in actual fact that the ROI is very difficult to apply to all projects, not just in terms of the subject diversification, but because of the poor understanding of "what to measure", when and how to measure this quantifiably (for example, there is no framework in place). Adding further to this point, one respondent commented that it was typical that BIM application was measured in "staff Professional Development Reviews (PDR's) but not recorded at a project level" which adds to the difficulties of measuring the benefits and lessons learned at the delivery stage of the system and not just peoples achievements. This said, some projects do receive benefits which were stated as not being "directly measured" when comparing one BIM project to another, as well as industry typically not specifying what the "benefits of BIM" adoption should be, and then measuring and managing these specifics in a targeted manner (Kim et al, 2013). The IPA report defines projects as reducing in confidence in them being delivered on time and budget as shown in Table 5. Taylor (2007) affirms this in that a reason for the lack of positive return and success is due to 'a poor understanding of how technology is implemented' at the delivery stages of Design and Construction projects.

Moreover, fragmentation between developed standards and people being able to firstly understand them then apply at a local level is clear both from data collected at the interview stage. This is also visible in quantifiable figures measured by the IPA and the 'lack of agreed value' of BIM from academia (Chinowsky and Rojas, 2003). Data from the IPA report in 2019-2020 shows that 45\% of the 'red' rated project confidence is directly associated to the Infrastructure and Construction sector, which outlines again issues with practical application of BIM across a diverse range of projects. Barlish and Sullivan (2012) argues that one of the issues of poor measurement is that there 'are no definite measures to the benefits of BIM in use', which shines focus on a disconnect between theoretical application and real-world situations.

Further, feedback from industry following data collection and analysis was that there is a perception that Client understanding is limited on how to adopt, practically administer BIM and govern BIM, and the "further that you go up the hierarchy", a disconnect appears from the value and an appreciation of the upfront effort that BIM requires. It is also believed that this is the case because Clients seem BIM as a "technology tool", when in actual fact it is an all-encompassing "set of processes" and methodologies positioned to improve quality, whilst advancing the measurement, management and proactive governance of project delivery (across all stages of the lifecycle).

Reoccurrences and trends linked to people being overwhelmed by the nature of BIM (standards, toolsets and conventions) alongside the theoretical methodology and mandatory requirements have resulted in reduced effectiveness and compacted understanding from staff of why they are implementing BIM and other Digital Engineering processes, procedures and tools.

Quantifiable measurement as progress is made in terms of goal achievement, alignment with requirements for the application of BIM alongside measuring the success of goals and outcomes is perceived as "too difficult" from industry experts, with evidence from Barlish and Sullivan (2012) stating there is 'no universal benefit of BIM' from either an academic or industrial perspective, without an objective focus. This is also reaffirmed in the IPA report findings in the form of disproportionately low confidence ratings specifically within the Infrastructure and Construction sector. In plain language, BIM out of the Box simply doesn't add a benefit by itself, and a lack of project comparators (BIM v Non-BIM), coupled with no quantifiable measurement or approaches with objective focus measurements appear to reaffirm this, as mirrored by Ibbs et al (2007).

Further, the IPA report(s) shows that across the diverse category of Infrastructure and Construction, data within shows a common trend that the success of projects being delivered on time and budget is actually reducing year on year, despite the UK Government Strategy (HM Government, 2011) statement of achieving '20\% savings' plus additional benefits and advantages via collaborative BIM adoption and implementation. Further to this, interviewee data shows that the benefit and gain to be had from BIM at the implementation stage relied upon "data appropriation" and by removing the "specialisms" required as they were "confusing and prohibitive", which results in a need for a clearer way of removing clutter, creating clarity and advancing towards benefit realisation. 
Despite the development of UK BIM Standards and Frameworks (UK BIM Alliance, 2020) agreements from several industry experts outlined that the deliverable process hasn't radically changed to accommodate BIM requirements, but rather a "different language" and "more toolsets" were needed to deliver Design and Construction via BIM. Eadie et al (2014) states that 'managers are reluctant to add new processes and technology' which explains alongside industry feedback why there is a competing set of old and new procedures will little ROI due to BIM. Effectively, these competing processes are doubling workloads (Hardin and McCool, 2015), exacerbating errors and requiring staff to have a heightened understanding of the methodologies, which ultimately results in inefficiencies gained alongside an increased cost in software, training and of course, time delays.

Further comparative conclusions are evident and common throughout in that new processes (such as BIM) are more often 'bolted' onto existing frameworks with a reduction in assertiveness in terms of the application and governance despite them being mandated from the UK Government on all publicly awarded contracts from 2016 onwards. Further and due to this, industry experts felt within the interviews undertaken most of the benefits gained from adopting BIM were merely "talked about" qualitatively, and were difficult to quantitatively measure, primarily due to the lack of a measurement and assurance frameworks/system available at a project delivery level.

Furthermore, evidence confirms that there is a poor connection between the design, construction and operational stages in terms of an agreed and seamless transfer of information, as well as other benefits that are being lost, such as unifying and collaborating systems to improve efficiencies across jurisdictions, using BIM for a defined purpose and as previous, measuring success. Adding to this, other than utilising " $3 \mathrm{D}$ models" for time sequencing and planning, a missing part of the value of BIM was seen to be the "data management" and more so the ability to manage, measure and deliver projects by utilising information in a more coordinated and considered way. Again, this is where objective focus is missing, which would have a high likelihood of enabling them to be delivered on time, on budget and to an improved standard, respectively.

It is also evident that in 2010 the IUK Infrastructure Cost Review (ICE, 2015) outlined that the typical costs of project delivery are ' $40 \%$ higher' specifically due to poor production management and pressure to deliver projects which can be likened to BIM (a new applied methodology). Fortune (2006) reaffirms this by stating this is partly due to 'no whole project delivery review of project performance'.

Finally, it is very important to remember that although BIM is an information delivery process that utilises advancements in technology for quality assurance/improvement, as well as enabling advancements and collaboration in modelling techniques (3D, 4D, 5D), it is in fact mostly intrinsically cultural and driven by people, who are supported and assisted by Digital technologies, toolsets and processes.

\subsection{Conclusive Remarks}

The purpose of the research methodology herein was to broadly investigate the adoption issues of BIM across academic literature and industrial reports, alongside interviewing implementation stakeholders who were responsible for delivering BIM on construction infrastructure projects. Findings within this paper show that although there are clear opportunities for the benefits to be achieved via the adoption of BIM across the entire lifecycle of a project, there is a gap between the theory and realised benefits at the application stage by industry.

For example, proportionate application is key in ensuring that goals are aligned, agreed and a measured via a methodology throughout the entire delivery cycle and not limited to a single stage or isolated task. This is also alongside setting appropriate goals and adjusting them accordioning, which provides a consistent focus on what the intention of the outcome should be, because of BIM. Further, a clear and understandable strategy of what to apply and when to do so for those who aren't necessarily BIM specialists is required to break down the barriers of confusion and seeing existing tasks such as BIM Execution Plans (BEP's) and model coordination meetings a hinderance not a help.

In response to this, a solution framework focused on improving current practices and to enhance adoption and transparency to teams across all project delivery has been proposed in Figure 8 below. The framework aims to deconstruct BIM into its constituent parts of objective focus which will better enable stakeholders in a) determining their problems and desires, 2) reviewing the impacts, dependencies and core requirements of the objective(s) and 3) selecting how the objective(s) will be delivered, who will be responsible and creating a measurement criteria to drive success or counter negative impacts stifling adoption. 
This then enables stakeholders to holistically address their use of BIM and thus more likely to remove the barriers of confusion whilst improving productivity, increasing in quality of outputs, enhancing collaboration and transparency of object focus. This also creates an opportunity to develop quantitative and qualitative measurements alongside the concentrated areas, which allow increased visibility of the ROI of applied BIM.

In addition, the solution framework positions the objective setting of targets directly towards the project requirements, in order to break down cultural and hierarchical barriers, whilst increasing the understanding of desires and opportunities centrally for discussion and agreement. This is rather than the current method of assigning a goal simply to the core BIM team, as this is one of the areas that drives reduced understanding and poor governance/acceptance of BIM at a delivery level.

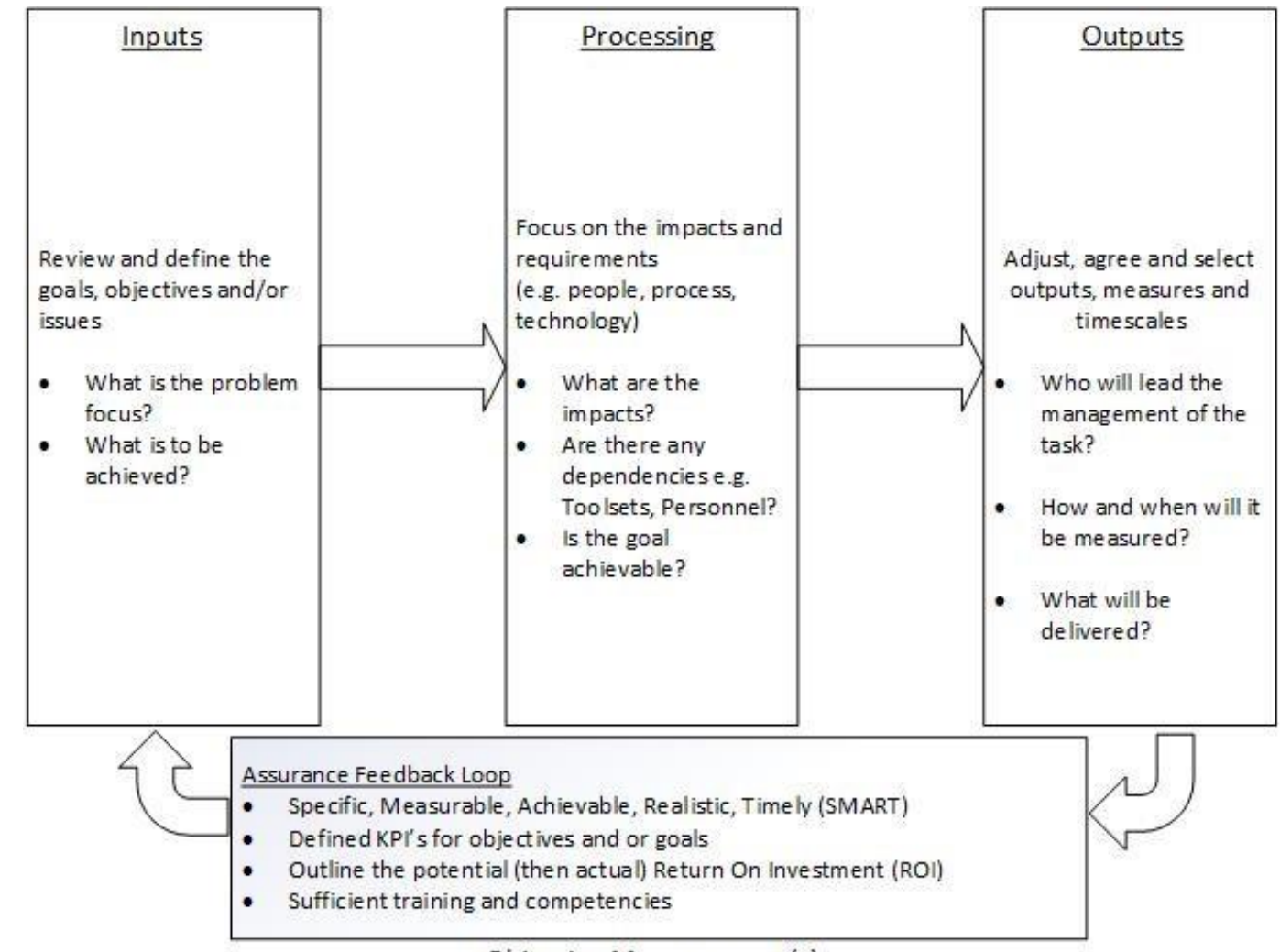

Objective Measurement(s)

FIG. 9: Proposed solution framework for targeting objective focus alongside the measurement of BIM goals and objectives

Finally, an assurance feedback loop is added to the framework to further ensure that the objectives, the impacts and the outputs are sufficiently clear and proportionate. Further, KPI's development is proposed with a review of staff suitability (skills and qualifications) to improve BIM adoption and gain benefits measured both qualitatively and quantitively.

\subsection{Limitations}

Some of the limitations faced within this research are as follows:

- Although there is a diverse range of industry experts across design and construction sectors, 10 out of 11 questions were predetermined which may have focused the study too directly;

- Industrial research topics were centralised around the 2019-2020 IPA Annual Report and could potentially limit the data analysis (IPA reports however are produced centrally by the UK Government for all publicly awarded contracts (BIM requirement as standard)); and

- The latter statement said, there is limited data available at a project and/or client level in terms of quantitative reporting of progress, advantages and benefits of BIM from industry at the application stage. 


\subsection{Future Works}

Following the findings within this paper and the framework solution outlined within Figure 9, there is an advantage and benefit in exploring further the impacts of objective/goal outcome focus of BIM, as well as developing the framework further by integrating across both qualitative and quantitative measurement formats. The benefit is in order to align the application and implementation of BIM towards objective goal achievement and thus increase the benefit at the execution and deliver stages respectively via people, processes and technologies.

\section{ACKNOWLEDGEMENTS}

The authors would like to thank Bjarnhedinn Gudlaugsson, a PhD research student of energy systems dynamics at the School of Computing, Engineering and Digital Technologies, Teesside University, for his guidance in the initial structure of this research.

\section{REFERENCES}

A14 Cambridge to Huntingdon Improvement Scheme (2019), https://highwaysengland.co.uk/a14-cambridge-tohuntingdon-improvement-scheme-progress/ (accessed 13/07/2020)

Akponeware et al. (2017), Clash Detection or Clash Avoidance- An Investigation into Coordination Problems in 3D BIM, School of Civil and Building Engineering, Loughborough University

Aljumaiah B. (2020), BUILDING INFORMATION MODELING TO CITY INFORMATION MODELING (BIM to CIM), Eastern Province Municipality

Barlish, K. Sullivan, K (2012), How to measure the benefits of BIM - A case study approach, Automation in Construction 24 (2012) 149-159

Baumeister R. F., Leary M.R. (1997), Writing narrative literature reviews. Review of General Psychology

Bernard H. (1988), Research Methods in Cultural Anthropology. Newbury Park, California: Sage.

Borenstein M., Hedges L., Higgins J., Rothstein H. Introduction to meta-analysis. Hoboken, nj: John Wiley \& Sons Inc; 2009

Braun, V., \& Clarke, V. (2013). Successful qualitative research: A practical guide for beginners. London, UK: SAGE.

Braun, V., Clarke, V., \& Terry, G. (2014). Thematic analysis. In P. Rohleder \& A. Lyons (Eds.), Qualitative research in clinical and health psychology. Basingstoke, UK: Palgrave MacMillan.

Racha Chahrour, Mian Atif Hafeez, Ahmad Mohammad Ahmad, Hashim Ibnauf Sulieman, Huda Dawood, Sergio Rodriguez-Trejo, Mohamad Kassem, Khalid Kamal Naji \& Nashwan Dawood (2021), Costbenefit analysis of BIM-enabled design clash detection and resolution, Construction Management and Economics, 39:1, 55-72, DOI: 10.1080/01446193.2020.1802768

Chilban J. (1996), Interviewing in Depth: The Interactive Relational Approach. Thousand Oaks, California: Sage.

Chinowsky, P.S. and Rojas, E.M. (2003). Virtual teams: Guide to successful implementation.” Journal of Management in Engineering, 19(3) 98-106.

CITB (2018), Industry Performance Reports, https://www.greenwoodconsultants.com/knowledge/industryperformance-reports/ (accessed 08/01/2021)

Cohen, M. (2017). A systematic review of urban sustainability assessment literature. In Sustainability (Switzerland) (Vol. 9, Issue 11). MDPI AG. https://doi.org/10.3390/su9112048

Constructing Excellence (2014), BIM Case Studies, https://constructingexcellence.org.uk/digital/bim-casestudies/ (accessed 02-03-21)

Corbin J, Strauss A (2008), Basics of Qualitative Research: Techniques and Procedures for Developing Grounded Theory, 3rd ed. Thousand Oaks, California: Sage Publications; 2008.

Dawood (2010), Development of 4D-based performance indicators in construction industry, Engineering Construction \& Architectural Management

Denzin, N (1989), Interpretive Biography, Volume 17 of Qualitative Research Methods, SAGE 
Doloi, H (2013), Cost Overruns and Failure in Project Management: Understanding the Roles of Key Stakeholders in Construction Projects, Journal of Construction Engineering and Management 139(3):267279

Eadie, R., Odeyinka, H., Browne, M., McKeown, C., \& Yohanis, M. (2014). Building information modelling adoption: an analysis of the barriers to implementation. Journal of Engineering and Architecture, 2(1), 77-101.

Ellis (2019), REBIM: Will ISO19650 replace BS1192, (https://rebim.io/goodbye-bs1192-hello-iso19650/ (accessed 14/07/2020)

Fortune, C. (2006). "Process standardization and the impact of professional judgement on the formulation of building project budget price advice.”Constr. Manage. Econ., 24(10), 1091-1098.

Fraley, R. C., \& Vazire, S. (2014), The N-pact factor: Evaluating the quality of empirical journals with respect to sample size and statistical power. PloS one, 9(10), e109019.

DOI: https://doi.org/10.1371/journal.pone.0109019 (accessed 15-03-2021)

Glaser, B., \& Strauss, A. (1967). The Discovery of Grounded Theory: Strategies for Qualitative Research. Mill Valley, CA: Sociology Press

Gray DE. (2009), Doing Research in the Real World, 2nd ed. Thousand Oaks, California: Sage Publications.

Greenwood Consultants (2020), Measuring Collaboration, https://constructingexcellence.org.uk/wpcontent/uploads/2020/10/GCR-CEPMF002_MeasuringCollaboration_20201014_Rev2.pdf (accessed 0203-21)

Hardin, B. McCool, D. (2015), BIM and Construction Management; Proven Tools, Methods and Workflows, Wiley 2nd Edition

Hart, C. (2001). Doing a literature search. London: Sage

Highways England (2019), A14 What we've delivered, https://highwaysengland.co.uk/our-work/a14-cambridgeto-huntingdon/what-we-ve-delivered/ (accessed 08-01-21)

HM Government (2011), Prime Ministers Mandate for the Major Projects Authority, https://assets.publishing.service.gov.uk/government/uploads/system/uploads/attachment_data/file/378509 /PM_mandate_for_MPA_2011.pdf (accessed 08/01/2021)

HM Government (2020), National Infrastructure Strategy, https://www.gov.uk/government/publications/national-infrastructure-strategy (accessed 02-03-21)

Institute of Civil Engineers (ICE) (2015), Production Management in Design and Construction, ICG Guideline, 2015

Infrastructure and Projects Authority (IPA) Mandate (2021), https://assets.publishing.service.gov.uk/government/uploads/system/uploads/attachment_data/file/949868 /IPA_Mandate_2021.pdf (accessed 10-02-21)

A. Hore, R. Montague, K. Thomas, F. Cullen, (2011), Advancing the use of BIM through a government funded construction industry competency centre in Ireland, CIB W78 2011: 28th International Conference, Paris, 26-28 October 2011, 2011.

Holton GJ (1973), Thematic origins of scientific thought: Kepler to Einstein. Cambridge, MA: Harvard University Press

W. Ibbs, L.D. Nguyen, L. Seulkee, (2007), Quantified impacts of project change, Journal of Professional Issues in Engineering Education and Practice (2007) 45-52.

Infrastructure and Projects Authority (2020), Annual Report on Major Projects 2019-20, https://assets.publishing.service.gov.uk/government/uploads/system/uploads/attachment_data/file/899401 /IPA_AR_MajorProjects2019-20.pdf (accessed 11/07/2020)

M. Kagioglou, R. Cooper, G. Aouad. (2001), Performance management in construction: a conceptual framework, Constr. Manag. Econ. 19 (1), 85-95. 
Kim, H. Anderson, K. Lee, S,H. Hildreth, J. (2013), Generating construction schedules through automatic data extraction using open BIM (building information modeling) technology. Automation in Construction, $\mathrm{v}$. 35, p. 285-295, 2013. DOI: https://doi.org/10.1016/j.autcon.2013.05.020.

Kirby-Turner C, Whittington C. (2018), BIM, Collaboration and NEC4, https://www.constructionmanagermagazine.com/bim-collaboration-and-nec4/ (accessed 20/07/2020)

Khosrowshahi, F. and Arayici, Y. (2012), Roadmap for implementation of BIM in the UK construction industry, Engineering, Construction and Architectural Management, 19(6), 610 - 635.

Lynch Construction (2019), A14 Case Study, https://www.l-lynch.com/A14-case-study/ (accessed 14/07/2020)

Maxwell, J. A. (Ed.). (2005) Qualitative research design: An interactive approach (2nd ed.). Thousand Oaks, CA: Sage

Mckinsey (2017), Reinventing Construction through a Productivity Revolution, https://www.mckinsey.com/industries/capital-projects-and-infrastructure/our-insights/reinventingconstruction-through-a-productivity-revolution (accessed 14/07/2020)

Olawumi, T.O., et al., (2018), Barriers to the integration of BIM and sustainability practices in construction projects: A Delphi survey of international experts. Journal of Building Engineering, 20, 60-71.

National Audit Office (2020), Lessons Learned from Major Programmes

Ojo and Pye, (2020), BIM Implementation Practices of Construction Organisation in the UK AEC Industry

Paré G., Trudel M.-C., Jaana M., Kitsiou S. (2015), Synthesizing information systems knowledge: A typology of literature reviews. Information \& Management. 2015;52(2):183-199.

The PRISMA Group (2009), Preferred Reporting Items for Systematic Reviews and Meta-Analyses: The PRISMA Statement. Open Med 2009; 3(3); 123-130

Rawlinson (2015), Procurement Update BIM, https://www.arcadis.com/media/D/F/5/\%7BDF5E5E67-DB174196-8FBB-

D66136F8E076\%7D9451_Simon\%20Rawlinson\%20Buildings\%20Insight\%20FINAL\%20WEB.pdf (accessed 19/07/2020)

Rossman, G. B., \& Wilson, B. L. (1985). Numbers and words: Combining quantitative and qualitative methods in a single large-scale evaluation study. Evaluation Review, 9(5), 627-643

Da Silva P.H, Crippa J, Scheer S (2019), BIM 4D in Construction Scheduling; Details, Benefits and Difficulties, PARC Pesquisa em Arquitetura e Construção 10:19010

Strauss, A., \& Corbin, J. (1994). Grounded theory methodology: An overview. In N. K. Denzin \& Y. S. Lincoln (Eds.), Handbook of qualitative research (p. 273-285). Sage Publications, Inc.

Taylor, J. E. (2007). "Antecedents of Successful Three-Dimensional Computer-Aided Design Implementation in Design and Construction Networks." Journal of Construction Engineering and Management, 133(12), 993-1002

Ustinovičius et al., (2018), Challenges of BIM technology application in project planning

UK BIM Alliance (2020), The UK BIM Framework and the UK BIM Alliance, https://www.ukbimalliance.org/wp-content/uploads/2020/03/Paul_Wilkinson_UKBIMA.pdf (accessed 18/12/2020)

HM Government (2012), Government Construction Strategy, https://assets.publishing.service.gov.uk/government/uploads/system/uploads/attachment_data/file/61157/ Procurement-and-Lean-Client-Group-Final-Report-v2.pdf (accessed 12/07/2020)

Young, N. W., Jones, S. A., Bernstein, H. M., and Gudgel, J. (2009).“The Business value of BIM-Getting building information modeling to the bottom line."SmartMarket Rep., McGraw Hill Construction, Bedford, MA

Zuppa, D. Issa, R. Suermann, C. (2009), BIM's Impact on the Success Measures of Construction Projects, Conference Paper in Journal of Computing in Civil Engineering · June 2009 


\section{APPENDICES}

\section{Appendix A - Interview Questions}

The semi-structured interview questions placed to the respondents as part of the data collection process were as follows:

1) In your opinion, has the development of the BIM Standards, Methods and Procedures helped with the adoption and implementation across industry? If yes how and if not, then why?

2) How do you/we measure and share the qualitative and quantitative benefits/lessons learned of BIM?

3) Why do you believe that reporting from the Infrastructure Projects Authority (IPA) and Constructing Excellence show no significant increase in productivity, cost and time improvement and general lack of return on investment since 2011 despite government mandating BIM?

4) When implementing, procuring, or supporting BIM what are your three desires (in terms of outputs) and conversely what are your three pain points?

5) Adding to question above, what are the benefits and inefficiencies resulting from adopting BIM?

6) More generally, who on your Project (in terms of role/function) do you feel 'gets' BIM and conversely who struggles and why?

7) When instructed to deliver projects to or accept into operations assets that have BIM requirements, what are your initial thoughts?

8) In your opinion, who gets the most benefit from adopting BIM i.e., clients. designers, contractors, maintainers, supply chain or other parties like local authorities and why?

9) When measuring the success of BIM adoption and Implemented on projects across Design, Construction and Operations perspectives when and how is it measured and who measures this?

10) Following Q9, in terms of goals and objectives for the use of BIM and Digital tools/methodologies, when are these reviewed and how is success measured, reported and if required alternatives put in place to bring the goal/objective back on track? [qualitatively and quantitatively]

11) Anything else to add from Interviewee? 